\title{
CURRENT TRENDS IN DENTAL EDUCATION
}

\author{
Ayesha Ghassan, Irfan Shukr, Naushaba Sadiq*, Rabia Ahsan** \\ Foundation University Medical College, Islamabad Pakistan, *National University of Medical Sciences (NUMS) Rawalpindi Pakistan, **Armed Forces Institute of \\ Dentistry / National University of Medical Sciences (NUMS) Rawalpindi Pakistan
}

\begin{abstract}
The dental profession is an important segment of human health care services all over the world. Dental schools in Europe and United States have evolved their curriculum to keep abreast with advances in dentistry; like connective tissue biophysics and molecular engineering through an objectively structured and clinically oriented curriculum. However, dental education in our country is still mostly traditional. This article examines the new approaches to teaching and learning in dental schools/ colleges that are shaping dental curriculum globally. Articles relating to curricular trends in dental education and advancement in the dental profession published between 2010-2020 were searched in medical search engines. However, few relevant articles published before this period were also consulted. The current trends in dental curricula show new teaching, learning, and assessment methods like small group discussions, case-based learning, competency-based learning, Inquiry-based teaching-learning, and peer-assisted learning. The curricular format is integrated and new innovative assessment techniques like the assessment of multiple systematic reviews (AMSTAR) are being employed. Virtual reality, interdisciplinary teaching, and distributed community models in dental education are being implemented. The emergence of COVID-19 has also affected dental education and as a result, e-learning formats and assessment techniques have become increasingly popular.

Dental schools abroad have revamped their curriculum with the advances in newer technologies and research related to dentistry. There is a need to immediately update and redesign the present dental curriculum in our country as well.
\end{abstract}

Keywords: Dental curricula, Entrustable professional activities, Innovative assessment techniques.

This is an Open Access article distributed under the terms of the Creative Commons Attribution License (https://creativecommons.org/licenses/by-nc/4.0/), which permits unrestricted use, distribution, and reproduction in any medium, provided the original work is properly cited.

\section{INTRODUCTION}

The dental profession is an important segment of human health care services all over the world and it is rapidly evolving as new technologies are developed. Advances in tissue and molecular engineering, biophysics, and biotechnology (gene therapy, drug pharmacokinetic, etc.) have ushered dentistry into a new era. Similarly, diagnostic approaches and therapeutic modalities have also been revolutionized e.g. computeraided design (CAD) and computer-aided manufacturing (CAM) improving patient care and decreasing patient visits ${ }^{1}$. Dental schools in Europe and United States have accordingly evolved their curriculum to keep abreast with these advances through a new research-based, objectively structured, and clinically oriented curricu-lum that meets the needs of students and the com-munity as well. However, dental education in our country is still predominantly traditional. The methods followed are predominantly instructional and taught as discipline-based in the form of lectures with emph-asis on technical expertise. Reasoning/analytical skills, upgrading content and teaching approaches are vastly neglected areas. Hence, there exists

Correspondence: Dr Ayesha Ghassan, Assistant Professor, Foundation University Medical College, Islamabad, Pakistan

Received: 18 Feb 2021; revised received: 22 Apr 2021; accepted: 28 Apr 2021 an urgent need to revitalize our current dental curriculum, education format, and technical expertise to incite critical thin-king and problem-solving skills in our dental students and bring them to par with dental graduates internationally. This report examines the new approaches to teaching and learning in dental schools/colleges that are shaping dental curriculum globally.

This report aims to provide a useful insight into current trends in dental education, to guide policy-makers, deans of dental colleges, curriculum and course leaders, teachers, researchers, administrators, and those responsible for accreditation procedures.

\section{METHODOLOGY}

An initial exploratory search for articles relating to curricular trends in dental education and advancement in the dental profession was carried out on medical search engines like Pub Med, Google Scholar, and Cochrane library. Pertinent material was selected, followed by a more detailed review to shortlist those published between 2010-2020; however few relevant articles published before this period were also consulted. Preference was given to articles, editorials, and survey reports appearing in indexed journals of international repute like Academic Medicine, Journal of American Dental Association, and Journal of Dental Education. 


\section{RESULTS}

The current trends in dental curricula show a comprehensive approach based on new teaching, learning, and assessment methods. These are as follows:

\section{Teaching and Learning Methods}

Appropriate learning strategies and intellectual tools are being devised to empower students with the required expertise to serve the community. Some of these methods are discussed below:

\section{Small Group Learning}

Several institutions haveinitiated small-group learning in form of either problem-based learning (PBL) or a hybrid variation between PBL and traditional methods. PBL-enhanced curriculum improves problemsolving and analytical thinking skills and personal and interpersonal attributes ${ }^{2}$. The earliest adopter of this system was the Harvard School of Dental Medicine. A study by Schotanus et al, in 2008 compared the longitudinal effects of PBL and traditional curricula among medical students at the University of Groningen ${ }^{3}$. Data suggested that students who underwent a PBL curriculum scored higher on general competencies when compared to those trained in a traditional curriculum.

\section{Case-based Learning}

Another learning technique is case-based learning in which the students solve the clinical cases by recalling topics taught earlier ${ }^{4,5}$. In comparison to PBL it is less resource-intensive and more cost effective.

\section{Competency-Based Learning}

Competency in any profession and in particular dentistry nourishes with experience. This method focuses on learning outcomes and not on learning objectives. Therefore, in contrast to traditional or disciplinebased approach, the learning outcomes are specified in competency-based learning ${ }^{6,7}$.

\section{Inquiry-based Learning}

Inquiry-based teaching-learning (IBTL) is a learning and knowledge development technique without specified limits. The students learn topics and skills in the form of inquiry and adaptively increase their knowledge base ${ }^{8}$.

\section{Peer-assisted Learning}

Peer-assisted learning (PAL) is a learning technique that has been present informally for quite some time and assists student learning in post-graduate institutes. PAL has lately been formally applied in dental education so that student tutors engage in better comprehension of knowledge content and development of their professional traits. It is defined as people (not professional teachers) of comparable standing, assisting each other to learn and learning themselves by teaching i.e., both tutees and tutors benefit from the transaction ${ }^{9}$. This method enables the identification of individual and group learning needs, promotes organization of existing knowledge, acquisition of new knowledge, critical thinking, socialization, and teamwork skills ${ }^{10}$. Ehsan et al 2020 recommended that instead of utilizing PAL as an independent tool of instruction for undergraduate dental students it should be an adjunct to synchronous teaching telepresence by faculty especially during the current COVID pandemic situation. She observed that students only tutored through PAL sessions scored less compared to those taught by expert-assisted learning ${ }^{11}$.

\section{Team-based Learning}

Another analogous active learning method is team-based learning (TBL). It is student-centric and holds him or her accountable for their class engagement preparation and to apply knowledge to solve real problems. A hybrid method that combines PAL with TBL can provide immediate feedback to the student from peers and therefore contributes to learning through formative assessment.

Another benefit of PAL/TBL is that personal attention can be given without the stress of assessment ${ }^{12}$. A study conducted by Nallaswamy et al, showed that this teaching method was extremely efficient ${ }^{13}$.

\section{Integrated Curricular Format}

There is an increasing trend to organize dental curriculum beyond the boundaries of a discipline, where the topics are taught by teams composed of subject specialists. Internationally the focus of the dental curriculum has increased towards community-based care and there is an early exposure of students to clinical experience through student-patient interactions. In America, competency-based education is being implemented and the involvement of students in the evaluation of curricula is generally being practiced ${ }^{14}$.The Case Western Reserve University and the University of Missouri-Kansas City were among the pioneer institutes to implement this model of teaching, and now multiple institutes have developed academic models where dental students manage different aspects of patient's disease.

\section{Innovative Assessment Techniques}

Alternative methods for assessment of student performance are now being used as better and more 
innovative teaching methodologies are available. One such method was used to assess how third-year dental students at Case Western Reserve University utilize assessment of multiple systematic reviews (AMSTAR) to evaluate systematic reviews in the context of an evidence-based, dentistry-oriented, and treatment planning course ${ }^{15}$.

\section{Simulation In Under-Graduate Dentistry}

Simulations have been used in dentistry since 1894; 'the phantom head' designed by Oswald Fergus was the first dental simulator ${ }^{16,17}$. Current advancements in virtual reality (VR) expertise like force-feedback haptic devices generate medical simulations of 3-dimensional images and environments, to provide near life scenarios to facilitate the transition from the dental school to the clinic.

All the phases of simulation activity play a significant role, and some researchers suggest that the debriefing phase is more beneficial than the actual simulation procedural activity ${ }^{18}$. Simulation in dental education has led to learning that is more efficient, increased effectiveness, standardized techniques, infinite training hours, and improved cost-effectiveness for dental colleges. However, initial setup costs, limited trained faculty, and limited spectrum of currently available content are few impediments to this high potential learning tool ${ }^{16}$.

Additionally, the introduction of life-like mannequins ensures that dental students acquire enough psychomotor skills to be prepared to accomplish various tasks in clinics. It is for these reasons that simulations and VR systems are being recognized as valuable tools for the training of dental students, and are being set up in dental schools around the world.

\section{Clinical Orientated and Research-based}

Internationally, there is a change towards a new curriculum that is clinically oriented, research-based, and objectively structured. The aim of such curricula is to produce dentists with a large knowledge base, an understanding of current scientific concepts in dentistry and at the same time vision to develop new approaches in the prevention and management of human diseases. The pivot of these curricula is on evidencebased clinical practices. Additionally, emphasis is being laid on the incorporation of medical jurisprudence and consumer in the new curricula.

\section{Distributed Community Models}

Another trend in dental curricula is the introduction of dental students spending more time in commu- nity clinics and practices ${ }^{19}$. Adental school in Arizona, USA has adopted a model in which community health centers are utilized as a vital element of students' clinical education ${ }^{20}$. Another aspect of this model is lectures and supervision in specific content areas by visiting faculty. Thedistributed community model has many financial benefits in terms of money saved to pay salaries and benefits for the faculty and the need for smaller on-campus clinical facilities.

The long-term sustainability of this model depends on variables like geographic factors, economics, and faculty resources. The Commission on Dental Accreditation now recommends that community-based dental education should be a significant component of the clinical education of all dental students ${ }^{19,21}$.

\section{Identifying and Improving Neglected Areas}

Presently in dental health education, oral health care education, prevention strategies and research infrastructure are neglected areas. Unfortunately, the response of government health related organizations and senior dental professionals to address these deficiencies are asthenic, marred by financial constraints, and myopic. Now in Pakistan, there is a strong desire to hire qualified individuals who havea global vision to objectively identify gaps in existing curricula and infrastructure, and revitalize ouracademia to keep us abreast with the modern world ${ }^{22}$.

\section{Interdisciplinary Teaching}

Interdisciplinary teaching for budding dentists in the different aspects of oral health is now a vital partof the reformed dental curriculum and is likely to expand further in the future ${ }^{21}$. We are now increasingly aware of the connections between general and oral health; and as a result, dentists will have to accept greater leadership roles to enhance oral healthin the general population ${ }^{23,24}$. Therefore, the dentists will have to acquire team management and collaborative work abilities.

\section{Teamwork}

Importance is being attached to improve teamwork between dentists, technicians, and health care professionals from other specialties. Literature search shows that interprofessional education is an emerging field within the oral health professions and students exposed to a formalized interprofessional curriculum are better prepared for collaborative practice ${ }^{25}$.

\section{Increasing Exposure of Students to Newer Technology}

As Iacopino noted, "It is generally accepted that most new practitioners use the technologies that they 
were exposed to and worked within their dental training and postgraduate residencies". Dental schools in the United States are increasing the exposure of their students to specific dental technologies like digital radiography, rotary endodontics, CAD/CAM denture fabrication, hard tissue lasers, etc. in the preclinical didactic phase ${ }^{1}$.

\section{Entrustable Professional Activities}

Entrustable professional activities (EPAs) are a crucial part of professional work that is entrusted to a trainee once sufficient competence has been achieved. They are well-defined, measurable, and relevant to dental practice and bridge the gap between competency-based learning and clinical practice. EPA framework outlines distinct tasks that learners are expected to perform independently after graduation ${ }^{26}$.

EPAs are monitored by direct or indirect supervision of the supervising doctor and later on assess by Objective Structured Clinical Examination (OSCE). In some of the institutes, successful trainees are given digital badges that not only serve as evidence of the skill acquired but also motivate other undergraduate trainees to achieve it. The digital badge also gives the detail of EPAs performed by the trainee.

\section{Communication Skills}

The communication between patient and dentist may impact the patient's wellbeing positively or adversely. Apropos, communication skills training (CoST) has been added to the curricula of several dental schools ${ }^{27}$.

There are many reasons as to why it has gained recognition; these include: (i) The complete care models of health require that dentists have communi-cation skills at par with those in other health professions; (ii) an environment of increased public focus toward issues in dental education regarding respectful communication and professionalism; and (iii) due to reports of negative experiences in dental clinics, dentists need to ease patient fear and anxiety effectively ${ }^{28}$.

In the CoST curriculum of dental students, activity focus is divided into two parts; didactic and experimental for each respective year of undergraduate training and it covers a variety of topics/scenarios likely to be faced by the future dentist.

\section{Critical Thinking}

Since 2013, dental colleges across America have started to teach and assess critical thinking in their students. This has occurred as a result of the new standards adopted by the Commission on Dental Accredi- tation (CODA) which are a reflection of the competencies set by the American Dental Education Association (ADEA) for the New General Dentist. The domain of critical thinking has steadily become more important due to rapidly expanding girth of information in dentistry and limited time available to impart it to the students ${ }^{29}$.

\section{E-Learning Formats for Teaching and Assessment}

Newer techniques like e-learning modalities are now available to assist teaching and learning through virtual classrooms and virtual learning environment. These may be used in any health professional undergraduate curriculum, including dental education, and have immense potential ${ }^{30,31}$. These e-learning modalities include asynchronous audio or video that comprises either of an audio or video file sent directly to a student's computer by the instructor; whereas, in synchronous audio or video a traditional lecture is broadcasted online to the students. In blended learning the instructions are provided through face-to-face teaching either online or computer-based. Multiple platforms for chat/video conferences are available, like Zoom or Skype. The discussions may be overseen by an instructor or they can be purely student-based. Computeraided learning is carried out through textual, pictorial, video, or interactive exercises with self-assessment questions and immediate feedback. e-PBL is carried out in a virtual learning environment; whereas, in ePortfolio the students build and maintain a digital repository of their activities and achievements. Another format is the online threaded discussion forum, where students answer or comment on a particular topic. In the repository and hypertext format, links to websites, an article or web pages containing information that the instructor wants the students to read or go through are shared online.

Similarly, online assessment techniques using inbuilt tools have been introduced for e-learning. These include automated comprehension-type exams suitable for convergent learning, many automated tools enable the creation of various question types e.g. True/false, MCQs, matching, ordering, etc. In text analysis format brief answers are graded, based ontext-analysis and full paperson the basis of text analysis algorithms. The student interactivity can be assessed by trained graduate teaching assistants (GTAs) on message boardswhere they interact and sharepresentations, text messages, pictorial graphs, article links, etc. Or they can be assessed through peer assessmentsin common learning forums where peers share their work with other mem- 
bers of the forum. Manual methods assess divergent learning via assessments of student papers and research projects, assessments of student designs, and assessments of portfolios.

Like medical education, dental education has also seen a rapid surge in online learning in the past decade $^{32}$. Boberick described the making and application of an interactive online pre-clinical guide for a course on restorative techniques. He showed that the guide effectivelyconveyed information beyond the textual format ${ }^{33}$. Similarly, Aly et al, showed that an interactive multimedia courseware package was equally effective when compared to standard lectures in orthodontics for undergraduate trainees ${ }^{34}$.

\section{Learning Management Systems}

The LMS enables the tracking of learners' participation and work overtime. It is an online platform being used in most of the medical and dental colleges across Pakistan during COVID pandemic. It integrates all learning resources and manages educational activities. It has a compilation of features and functions that supplement teaching and learning processes, e.g. course management tools, homework collections and grading, online group discussion, and course evaluation ${ }^{35}$. Several studies reveal that students who were part of web-augmented education displayed better scores. It was also considered beneficial and students reported positive attitudes toward it ${ }^{36}$. LMS can be of open source type or a commercially designed one. Both formats have their advantages and disadvantages, however commercial LMS is generally considered superior as it is customized. A dental college should opt for a system according to its needs and the resources available.

\section{Recommendations of Dental Accreditation and Licensing Associations}

Another factor that has greatly influenced alterations to dental educational models is the accrediting and licensing associations. The accreditation and licensing associations in America suggested key changes in the dental licensure process in September 2018. The Task Force opposed the use of single encounter, procedure-based examinations on patients. It recommended that instead of each state has its standards for issuing a practicing license, a common core of dentist credentials for issuing license be developed at the national level which can serve as a basis for licensure compacts between states. The national standard should be based on competency-based education being taught in accredited dental colleges and reliable new modalities of assessment. They also suggested that ADEA Competencies for the New General Dentist be an integral part of the procedure of granting a license and should include what a fresh dental graduateneeds to do to be successful in practice and to serve the public ${ }^{37}$.

\section{Impact of Covid on Dental Education}

During the COVID-19 crisis, the e-learning formats have gained additional importance as face-to-face lectures, instructive courses, presentations, seminars, and hands-on workshops have transitioned to online instruction. The challenges faced by faculty members for rapid adaptation of the entire curriculum and evaluation methods when shifting to an online platform were daunting. However, dental faculty across America created a curriculum onlineby employing video conferencing and file-sharing platforms to deliver virtual lectures, assist discussions, and encourage student involvement. One of the greatest challenges faced in implementation of this was ensuring attendance particularly for students residing in different time zones.

Another drawback of COVID was cancellation of external mandatory rotations of dental curriculum. Though activities with full precautions have resumed in some parts of the world; however, in most countries these have generally moved to tele-dentistry consultations. Now, a major concern of dental colleges and institutes is whether their students and residents are competent enough to clear the examinations of accreditation councils and more importantly to satisfy the patients. Currently, CODA has not changed its requirements despite the COVID-19 crisis $^{38}$.

A source of concern for fresh dentistry graduates is that many license awarding agencies are postponing their examinations. However, in a bit to tackle this issue in the USA, a new dental licensure objective structured clinical examination (DLOSCE) was created. It can reliably and precisely identify the clinical practices of the adjudged candidate ${ }^{39}$. This method is now also being used in Canada by the Dental Examining Board. It relies more on clinical judgment and decisionmaking rather than performing procedures on live patients.

One strong positive to emerge from COVID pandemic is the greater degree of collaboration across dental education community, especially in North America. Dental colleges and societies abroad have joined hands to offer free access to continuous dental education content and hold webinars to encourage professional collaboration and camaraderie. Dental faculty and support staff are putting in extra time to converse with stu- 
dents on a regular basis to allay their apprehensions and timely inform them of the latest news and decisions.

\section{Future of Dental Curriculum}

Future curriculum adjustments at dental colleges if not already implemented; include blending of basic and clinical sciences, multidisciplinary curriculum based on clinical themes, use of simulation and VR, competence assessment by new methods, and collaborations with medical colleges. This should be supplemented by simultaneously improving theteaching skills, curriculum planning, and assessment techniques of the faculty ${ }^{27}$.

\section{CONCLUSION}

The present dental curriculum in our country needs to be updated and reformed immediately keeping in vogue with the national and international requirements of dental profession. In this regard, a number of latest teaching and assessment techniques both face-to-face and online, and models of curriculum changes of dental schools in the USA are available which can be adopted in our country according to our needs and resources available.

\section{CONFLICT OF INTEREST}

This study has no conflict of interest to be declared by any author.

\section{REFERENCES}

1. Schwindling FS, Deisenhofer UK, Porsche M, Rammelsberg P, Kappel S, Stober T. Establishing CAD/CAM in Preclinical Dental Education: Evaluation of a Hands-On Module. J Dent Educ 2015; 79(10): 1215-21.

2. Allareddy V, Haven AM, Howell H, Karimbux NY. American dental education association evaluation of a new assessment tool in problem-based learning tutorials in dental education. J Dent Educ 2011; 75(5): 665-71.

3. Cohen-Schotanus J, Muijtjens AM, Schönrock-Adema J, Geertsma J, Van Der Vleuten CP. Effects of conventional and problembased learning on clinical and general competencies and career development. Med Educ 2008; 42(3): 256-65.

4. Fincham AG, Shuler CF. The changing face of dental education: the impact of PBL. J Dent Educ 2001; 65(5): 406-21.

5. Gooding HC, Ziniel S, Touloumtzis C, Pitts S, Goncalves A, Emans J, et al. Case-based teaching for interprofessional postgraduate trainees in adolescent health. J Adolesc Health 2016; 58(5): 567-72.

6. Nulty DD, Short LM, Johnson NW. Improving Assessment in Dental Education through a Paradigm of Comprehensive Care: A Case Report. J Dent Educ 2010; 74(12): 1367-79.

7. Albino JE, Young SK, Neumann LM, Kramer GA, Andrieu SC, Henson L, et al. Assessing dental students' competence: best practice recommendations in the performance assessment literature and investigation of current practices in predoctoral dental education. J Dent Educ 2008; 72(12):1405-35.

8. Nagda SJ. Changing trends in dental education-Paradigm Shift. J Dent Specialities 2015; 3(1): 86-88.
9. Al Kawas S, Hamdy H. Peer-assisted learning associated with team-based learning in dental education. Health Prof Educ 2017; 3(1): 38-43.

10. Pinho GC, Miranda EP, Tavares MD, Alves DV, Morais RX, Sobreira TM, et al. Peer-Assisted and Team-Based Learning: A new hybrid strategy for Medical Education. Rev Bras Educ Med 2018; 42(3): 162-70.

11. Ehsan AA. Peer-assisted learning (PAL) as an instructional tool in undergraduate dental education. J Coll Physicians Surg Pak 2020; 30 (11): 1184-87.

12. Al Kawas S, Hamdy H. Peer-assisted learning associated with team-based learning in dental education. Health Prof Educ 2017; $3(1): 38-43$

13. Nallaswamy D, Rangalakshmi S, Subha M. Peer assisted teambased learning in undergraduate dental education. Int J Pharm Sci Res 2019; 10(1): 607-11.

14. Haden NK, Hendricson WD, Kassebaum DK, Ranney RR, Weinstein G, Anderson EL, et al. Curriculum change in dental education, 2003-09. J Dent Educ 2010; 74(5): 539-57.

15. Teich ST, Heima M, Lang Lisa. Dental Students' Use of AMSTAR to Critically Appraise Systematic Reviews. J Dental Educ 2015; 79(9): 1031-39.

16. Perry S, Bridges SM, Burrow MF. A review of the use of simulation in dental education. Simul Healthc 2015; 10(1): 31-37.

17. Gottlieb R, Vervoorn JM, Buchanan J. Simulation in dentistry and oral health. InThe comprehensive textbook of healthcare simulation 2013 (pp. 329-340). Springer New York NY. [Internet] Available at: https://link.springer.com/chapter/10.1007/978-14614-5993-4_21.

18. Levett-Jones, T, Lapkin S. 'A systematic review of the effectiveness of simulation debriefing in health professional education'. Nurse Educ Today 2014; 34(6); e58-e63.

19. Formicola AJ, Bailit HL. Community-Based Dental Education: History, Current Status, and Future. J Dent Educ 2012; 76(1): 98 106.

20. Smith KP, Woldt JL, Cottam WW, Cederberg RA. The Arizona model: a new paradigm for dental schools. J Dent Educ 2011; 75(1): 3-12.

21. Commission on Dental Accreditation. Accreditation standards for dental education programs. Chicago: American Dental Association. [Internet] Available from: https://www.ada.org/ coda [Accessed on: November 12 2020].

22. Amin M. Dental Education in Pakistan: Current Trends and Practices. J Coll Physicians Surg Pak 2010; 20(8): 497-98.

23. Berg JH, Mouradian WE. Integration of dentistry and medicine and the dentist of the future: changes in dental education. J Calif Dent Assoc 2014; 42(10): 697-700.

24. Mouradian WE, Lewis CW, Berg JH. Integration of dentistry and medicine and the dentist of the future: the need for a health care team. J Calif Dent Assoc 2014; 42(10): 687-96.

25. Evans J, Henderson A, Johnson N. The future of education and training in dental technology: designing a dental curriculum that facilitates teamwork across the oral health professions. Br Dent J 2010; 208(5): 227-30.

26. Wolcott MD, Mason MR, Broome AM, Tittemore AJ, De Rossi SS, Quinonez RB. Faculty perspectives of an entrustable professional activity (EPA) framework in predoctoral dental education. J Dental Educ 2020; 84(9): 955-63.

27. Haden NK, Hendricson WD, Kassebaum DK, Ranney RR, Weinstein G, Anderson EL, et al. Curriculum Change in Dental Education, 2003-09. J Dent Educ 2010; 74(5): 539-57.

28. Ayn C, Robinson L, Nason A. Determining recommen-dations for improvement of communication skills training in dental education: A scoping review. J Dent Educ 2017; 81(4): 479-88. 
29. Saeed S. Evidence-based education: faculty development workshop to promote critical thinking skills in dental education. Mededportal 2017; 13(1): 10600-607.

30. Mattheos N, Stefanovic N, Apse P, Attstrom R, Buchanan J, Brown $\mathrm{P}$, et al. Potential of information technology in dental education. Eur J Dent Educ 2008; 12: 85-92.

31. Jawaid M, Aly SM. 'E-learning' modalities in the current era of medical education in Pakistan. Pak J Med Sci 2014; 30(5): 1156-58.

32. Chang HJ, Symkhampha K, Huh KH, Yi WJ, Heo MS. The development of a learning management system for dental radiology education: A technical report. Imag Sci Dent 2017; 47(1): 51-55.

33. Boberick KG. Creating a web-enhanced interactive preclinic technique manual: case report and student response. J Dent Edu 2004; 68(12): 1245-57.

34. Aly M, Elen J, Willems G. Instructional multimedia program versus standard lecture: a comparison of two methods for teaching the undergraduate orthodontic curriculum. Eur J Dent Educ 2004; 8(1): 43-46.
35. Albarrak AI, Aboalsamh HA, Abouzahra M. Evaluating learning management systems for University medical education. In 2010 International conference on education and management technology 2010 (pp. 672-677). IEEE. [Internet] Available from: https: //ieeexplore.ieee.org/abstract/document/5657569 [Accessed on November 10 2020].

36. Handal B, Groenlund C, Gerzina T. Dentistry students' perceptions of learning management systems. Eur J Dent Educ 2010; 14(1): 50-54.

37. Murdoch-Kinch CA. It's time to reimagine the "new dental graduate". J Dent Educ 2018; 82(11): 1123-26.

38. Wu DT, Wu KY, Nguyen TT, Tran SD. The impact of Covid-19 on dental education in North America-Where do we go next?. Eur J Dent Educ 2020; 24(4): 825-27.

39. Nieto VK, Eagle I, Mishler S, Rulli D. Utilization of Objective Structured Clinical Examinations (OSCE) as an Assessment for Clinical Competency and Licensure: A survey of dental hygiene directors' knowledge and attitudes. J Dent Hyg 2020; 94(6): 65-71. 